\title{
Microwave-Induced Synthesis of Some Novel Fungicidal Pyrazole Derivatives
}

\author{
A.D. Mishra ${ }^{*}$ \\ Tribhuvan University, Department of Chemistry, P.N. Campus, Pokhara, Nepal \\ E-mail: mishraad05@hotmail.com
}

\begin{abstract}
A series of novel pyrazole derivatives have been synthesized from propanoyl hydrazine and aromatic aldehydes under microwave irradiations. The reaction leads to condensation in ethanolic solution to give corresponding hydrazones which undergo subsequent cyclisation to furnish pyrazole derivatives in presence of formic acid. The reaction rate is enhanced considerably by using microwaves with excellent yield as compared to conventional heating method. The reactions took 4-7 minutes for completion with $78-92 \%$ yield. All the synthesized pyrazole derivatives showed promising antifungal activities against Aspergillus niger and Aspergillus Flavus. Microwave-induced organic synthesis has been proved quite beneficial and eco-friendly method in terms of limited use of chemicals, short reaction time and good yield with higher degree of purity.
\end{abstract}

Keywords: Pyrazoles, hydrazones, microwave irradiation, fungicidal, cyclisation, ecofriendly, solid support.

\section{Introduction}

Organic compounds coupled with heterocycles exhibit a wider range of pharmacological activities ${ }^{1-3}$ like fungicidal, bactericidal, viricidal etc. Heterocyclic compounds have been reported to be synthesized by various conventional methods ${ }^{4-6}$ which consume higher amount of reactants, solvents, catalysts, hazardous chemicals and tediously longer reaction time. Nowadays variety of heterocyclic compounds have been synthesized under microwave irradiations by using inorganic solid supports ${ }^{7-10}$ like acidic, basic and neutral alumina or montmorilonite $\mathrm{K}_{10}$ clay based on the reaction conditions. These solid supports act as catalyst as well as media for causing chemical reactions ${ }^{11,12}$. Solid supported microwave organic synthesis has been proved as an ecofriendly tool in pharmaceutical chemistry. ${ }^{13,14}$

The chemistry of pyrazoles is associated with diverse biological activities ${ }^{15-17}$ like antifungal, antibacterial, antiviral, antipyretic, antiseptic. etc. Various conventional methods have been reported for the synthesis of aromatic as well as aliphatic pyrazole derivatives ${ }^{18-21}$. A series of mercurial pyrazole derivatives have been synthesized as potential antifungal agents ${ }^{22,23}$ in solvent free conditions under microwave irradiations. Novel polysubstituted pyrazoles are synthesized herein from aromatic aldehydes and hydrazine derivatives along with the use of formic acid as cyclising agent under MWI and conventional heating methods to perform a comparative study and evaluation against different fungal strains.

\footnotetext{
* Corresponding author
} 


\section{Experimental Methods}

Microwave irradiation reactions were carried out in a Padmini Essentia microwave oven at 2450 $\mathrm{MHz}$ and the conventional reactions were carried out in RB flask fitted with air condenser on a calibrated magnetic stirrer. ${ }^{24}$ Melting points were recorded on a Thomas Hoover melting point apparatus and are uncorrected. IR spectra were recorded on FT Hitachi R-600 instrument using $\mathrm{KBr}$ pellets and the ${ }^{1} \mathrm{H}$ NMR spectra were recorded by using $\mathrm{CDCl}_{3}$ solvent on a Brucker $300 \mathrm{MHz}$ spectrometer with tetramethyl silane as an internal standard. The purity of the compounds was checked on silica gel coated Al plates (Merck). The chemicals used were purchased from SD fine chemicals Co. Ltd.

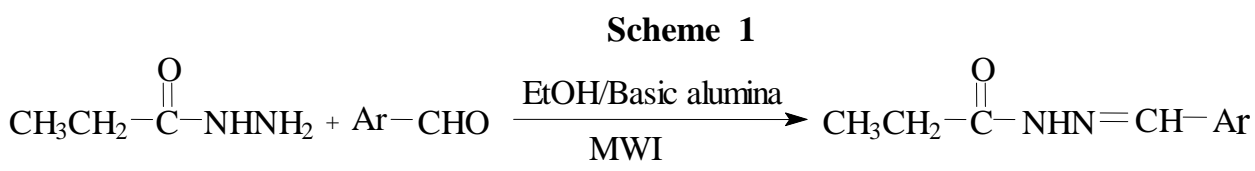

(1)

(2a-f) (3a-f)

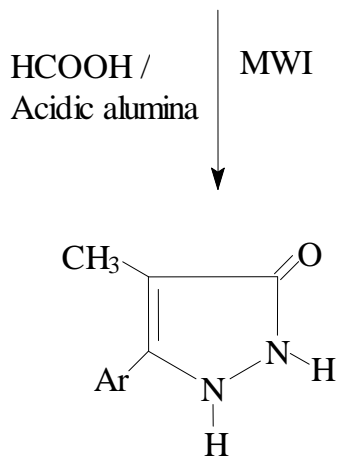

(4a-f)
$\mathrm{Ar}=\mathrm{a} \cdot \mathrm{C}_{6} \mathrm{H}_{5}$
b. $4-\mathrm{CH}_{3} \mathrm{C}_{6} \mathrm{H}_{4}$
c. $4-\mathrm{CH}_{3} \mathrm{OC}_{6} \mathrm{H}_{4}$
d. $2-\mathrm{OHC}_{6} \mathrm{H}_{4}$
e. $3-\mathrm{NO}_{2} \mathrm{C}_{6} \mathrm{H}_{4}$
f. $4-\mathrm{ClC}_{6} \mathrm{H}_{4}$

Propanoyl hydrazine (1) and propanoyl hydrazones (3a-f) were synthesized according to literature methods. ${ }^{25,26}$

General procedure for the synthesis of 3-aryl-4- methylpyrazol-3 -ene-5- ones, (4a-f)

\section{Conventional Method}

An equimolar amount ( 0.01 mole) of propanoyl hydrazone (3a-f) and formic acid was heated under reflux for 21-25 hours to get precipitate of the pyrazoles $(4 a-f)$. The reaction mixture was cooled and the solid separated out was filtered off, washed with water and recrystallized from ethanol.

\section{Microwave Method}

Propanoyl hydrazone (3a-f) and formic acid with the amount of 0.01 mole each were mixed together and the resulted mixture was adsorbed in 10 grams of acidic alumina in a small beaker which was then subjected to microwave irradiation at an interval of 30 seconds for 4-7 minutes. The progress of the 
reaction was monitored by thin layer chromatography. After the completion of the reaction, the content was cooled and eluted with ethanol batch wise $(4 \times 15 \mathrm{ml})$. Then the solvent was recovered from the extract through distillation under reduced pressure leaving behind pyrazole derivatives $(4 \mathrm{a}-\mathrm{f})$ in solid state. The product was washed with cold water followed by recrystallisation from ethanol.

\section{Results and Discussion}

Propanoyl hydrazine (1) was reacted with aryl aldehydes (2a-f) in ethanolic solution under the support of basic alumina in microwave irradiation to yield aryl hydrazones (3a-f). Hydrazones thus obtained were mixed with formic acid in equimolar amounts and adsorbed in acidic alumina followed by microwave heating to furnish corresponding pyrazoles (4a-f). Formic acid acts as cyclizing agent in this reaction. These reactions took 4-7 minutes for completion with 78-92\% yield in higher degree of purity. The reactions were carried out by conventional heating methods also for a comparative study, where the reactions took 21-25 hours for completion with 58-65\% yield (Table-1). The usage of hazardous solvents and poisonous chemicals is avoided in microwave reactions in pre and post reaction stages. Alumina acted as basic and acidic media. These observations have proved microwave reactions more ecofriendly and beneficial in terms of reaction time, yield and purity of the products.

Table-1: Reaction time and yield of pyrazoles, 4a-f

\begin{tabular}{|l|l|c|c|c|c|c|}
\hline Comp. & \multicolumn{1}{|c|}{$\mathbf{A r}$} & \multirow{2}{*}{$\begin{array}{c}\text { M.P. } \\
\text { no. }\end{array}$} & & \multicolumn{2}{c|}{ Conventional heating } & \multicolumn{2}{c|}{ Microwave irradiation } \\
\cline { 4 - 7 } & & Time (hrs) & Yield (\%) & Time (secs) & Yield (\%) \\
\hline $4 \mathrm{a}$ & $\mathrm{C}_{6} \mathrm{H}_{5}$ & 142 & 25 & 58 & 7 & 78 \\
\hline $4 \mathrm{~b}$ & $4-\mathrm{CH}_{3} \mathrm{C}_{6} \mathrm{H}_{4}$ & 168 & 24 & 59 & 6 & 80 \\
\hline $4 \mathrm{c}$ & $4-\mathrm{CH}_{3} \mathrm{OC}_{6} \mathrm{H}_{4}$ & 176 & 22 & 60 & 6 & 82 \\
\hline $4 \mathrm{~d}$ & $2-\mathrm{OHC}_{6} \mathrm{H}_{4}$ & 153 & 23 & 62 & 5 & 85 \\
\hline $4 \mathrm{e}$ & $3-\mathrm{NO}_{2} \mathrm{C}_{6} \mathrm{H}_{4}$ & 165 & 21 & 65 & 4 & 92 \\
\hline $4 \mathrm{f}$ & $4-\mathrm{ClC}_{6} \mathrm{H}_{4}$ & 172 & 22 & 63 & 5 & 89 \\
\hline
\end{tabular}

The structures of the synthesized pyrazoles (4a-f) were confirmed by spectral and analytical data (Table-2). Appearance of IR band at $1710-1725 \mathrm{~cm}^{-1}$ indicates the presence of cyclic ketonic group in the compounds. Similarly, a band at $3200-3225 \mathrm{~cm}^{-1}$ confirmed the presence of secondary amino linkage whereas IR band at $1580-1592 \mathrm{~cm}^{-1}$ is the indication of alkene bond in the compounds. Presence of hydroxyl, nitro, chloro and ether groups have shown their characteristic absorption bands in IR spectra (table 2). A broad singlet at 10.0-10.2 ppm in ${ }^{1} \mathrm{H}$ NMR confirmed the secondary amino proton in pyrazole linkage. All the aromatic protons appear at 7.4-7.6 ppm in ${ }^{1} \mathrm{H}$ NMR analysis and methyl protons in the heterocyclic ring have shown a singlet at $1.5-2.2 \mathrm{ppm}$.

Table-2 : Spectroscopic characterization of pyrazoles, 4a-f

\begin{tabular}{|c|l|l|}
\hline Comp. no. & \multicolumn{1}{|c|}{ IR, $\boldsymbol{v}\left(\mathbf{c m}^{-1}\right)$} & \multicolumn{1}{|c|}{${ }^{1} \mathbf{H}$ NMR, $\boldsymbol{\delta}(\mathbf{p p m})$} \\
\hline $4 \mathrm{a}$ & $\mathrm{N}-\mathrm{H}(3200)$ & $10.1(\mathrm{br}, 2 \mathrm{H}, 2 \times \mathrm{NH})$, \\
& $\mathrm{C}=\mathrm{O}(1710)$ & $7.4(\mathrm{~m}, 5 \mathrm{H}, \mathrm{Ar}-\mathrm{H})$, \\
& $\mathrm{C}=\mathrm{C}(1580)$ & $2.1\left(\mathrm{~s}, 3 \mathrm{H}, \mathrm{CH}_{3}\right)$ \\
\hline $4 \mathrm{~b}$ & $\mathrm{~N}-\mathrm{H}(3210)$ & $10.2(\mathrm{br}, 2 \mathrm{H}, 2 \times \mathrm{NH})$, \\
& $\mathrm{C}=\mathrm{O}(1720)$ & $7.5(\mathrm{~m}, 4 \mathrm{H}, \mathrm{Ar}-\mathrm{H})$, \\
& $\mathrm{C}=\mathrm{C}(1590)$ & $2.0\left(\mathrm{~s} .3 \mathrm{H}, \mathrm{CH}_{3}\right)$, \\
& & $1.5\left(\mathrm{~s}, 3 \mathrm{H}, \mathrm{CH}_{3}\right)$ \\
\hline
\end{tabular}


J. Nepal Chem. Soc., vol. 30, 2012

\begin{tabular}{|l|l|l|}
\hline $4 \mathrm{c}$ & $\mathrm{N}-\mathrm{H}(3215)$ & $10.2(\mathrm{br}, 2 \mathrm{H}, 2 \times \mathrm{NH})$, \\
& $\mathrm{C}=\mathrm{O}(1722)$ & $7.5(\mathrm{~m}, 4 \mathrm{H}, \mathrm{Ar}-\mathrm{H})$, \\
& $\mathrm{C}=\mathrm{C}(1595)$ & $2.7\left(\mathrm{~s}, 3 \mathrm{H}, \mathrm{OCH}_{3}\right)$, \\
& $\mathrm{C}-\mathrm{O}-\mathrm{C}(1210)$ & $10.8(\mathrm{~s}, 1 \mathrm{H}, \mathrm{CH})$ \\
& $\mathrm{O}-\mathrm{H}(3602)$ & $10.0(\mathrm{br}, 2 \mathrm{H}, 2 \times \mathrm{NH})$, \\
& $\mathrm{N}-\mathrm{H}(3220)$ & $7.6(\mathrm{~m}, 4 \mathrm{H}, \mathrm{Ar}-\mathrm{H})$ \\
& $\mathrm{C}=\mathrm{O}(1725)$ & $2.1(\mathrm{~s}, 3 \mathrm{H}, \mathrm{CH})$ \\
& $\mathrm{C}=\mathrm{C}(1592)$ & \\
& $\mathrm{C}-\mathrm{O}(1405)$ & $10.1(\mathrm{br}, 2 \mathrm{H}, 2 \times \mathrm{NH})$, \\
& $\mathrm{N}-\mathrm{H}(3225)$ & $2.5(\mathrm{~m}, 4 \mathrm{H}, \mathrm{Ar}-\mathrm{H}), 3 \mathrm{H}, \mathrm{CH})$ \\
& $\mathrm{C}=\mathrm{O}(1722)$ & \\
\hline $4 \mathrm{~d}$ & $\mathrm{C}=\mathrm{C}(1590)$ & $10.2(\mathrm{br}, 2 \mathrm{H}, 2 \times \mathrm{NH})$ \\
& $(\mathrm{NO})(1505)$ & $7.4(\mathrm{~m}, 5 \mathrm{H}, \mathrm{Ar}-\mathrm{H})$ \\
& $\mathrm{N}-\mathrm{H}(3220)$ & $2.0(\mathrm{~s}, 3 \mathrm{H}, \mathrm{CH})$ \\
& $\mathrm{C}=\mathrm{O}(1710)$ & \\
\hline $4 \mathrm{f}$ & $\mathrm{C}=\mathrm{C}(1585)$ & $\mathrm{C}-\mathrm{Cl}(850)$ \\
&
\end{tabular}

Pyrazoles $(4 \mathrm{a}-\mathrm{f})$ were tested against two fungal strains namely Aspergillus niger and Aspergillus flavus by paper disc diffusion method ${ }^{27,28}$ with salicylic acid as reference drug. The test compounds were dissolved in dimethyl formamide at a concentration of $50 \mu \mathrm{g} / \mathrm{ml}$ and the zone of inhibition was measured in millimeters. Pyrazoles $4 \mathrm{~d}$ and $4 \mathrm{f}$ have shown promising activities, $4 \mathrm{c}$ and $4 \mathrm{e}$ moderate and others have shown mild antifungal activities against the tested fungal strains (table 3 ).

Table- 3: Antifungal Activities of Pyrazoles, 4a-f

\begin{tabular}{|l|l|l|}
\hline Comp. no. & Aspergillus niger & Aspergillus flavus \\
\hline $4 \mathrm{a}$ & ++ & +++ \\
\hline $4 \mathrm{~b}$ & + & ++ \\
\hline $4 \mathrm{c}$ & ++ & +++ \\
\hline $4 \mathrm{~d}$ & +++ & ++++ \\
\hline $4 \mathrm{e}$ & ++ & +++ \\
\hline $4 \mathrm{f}$ & +++ & ++++ \\
\hline Salicylic acid* & +++++ & +++++ \\
\hline
\end{tabular}

* Reference drug: Zone of inhibition in $\mathrm{mm}$ for $50 \mu \mathrm{g} / \mathrm{ml}$ of the compounds: $+=3-10 \mathrm{~mm},++=11-14 \mathrm{~mm}$, $+++=15-18 \mathrm{~mm},++++=19-21 \mathrm{~mm},+++++=22-25 \mathrm{~mm}$.

\section{Conclusion}

Some novel pyrazole derivatives are synthesized from commonly available precursors under microwave irradiations with 78-92\% yield in 4-7 minutes. The method is accompanied with higher degree of purity and avoids the usage of expensive and hazardous chemicals. The solid supports and the solvents can be reused in this method. The conventional reactions took 21-25 hours for completion yielding only $58-65 \%$ products along with excess use of chemicals and solvents. Microwave irradiation method is thus proved to be an eco-friendly tool for synthetic works in green chemistry. Pyrazole derivatives synthesized herein are found fungicidal with moderate to excellent activities. 


\section{Acknowledgement}

The auther thanks the Department of Chemistry and the Department of Microbiology, Tribhuvan University, P.N. Campus, Pokhara, for providing laboratory facilities regarding synthesis and antimicrobial screening of the synthesized compounds. The research division of the campus deserves sincere thanks for providing research fund. Thanks are due to Department of Chemistry, Laboratory of Instrumentation, University of Delhi, for co-operation in analytical studies of the compounds.

\section{References}

1. G. Daidone, B. Maggio, D. Reffla, and M.L. Bajardi, Eur. J. Med. Chem., 1994, 29, 707.

2. G.A. Nawar, R.H. Swellen, and S.A. Osman, Heterocycles, 1992, 34, 457.

3. M. Kidwai, S. Kohli, and P. Kumar, J. Chem. Res., 1998, 5, 52.

4. A.D. Mishra, J. Nepal Chem. Soc., 2010, 25, 83.

5. A.D. Mishra, J. Nepal Chem. Soc., 2011, 27, 115.

6. A.D. Mishra, J. Nepal Chem. Soc., 2009, 24, 49.

7. S. Caddick, Tetrahedron, 1995, 51, 10403.

8. R.S. Varma, Green Chemistry, 1999, 1, 43.

9. R.C. Larock, and Y.D. Lu, Tetrahedron Lett. 1998, 39, 6761.

10. G. Bram, A. Loupy, and M. Majdoub, Tetrahedron, 1990, 46, 5167.

11. K. Eger, G. Grieb, and S. Spatting, J. Heterocyclic Chem., 1990, 27, 2069.

12. M. Kidwai, and A.D. Mishra, J. Nepal Chem. Soc., 2007, $22,1$.

13. B.S. Jursic, Synth. Commun., 1993, 23, 361.

14. R.N. Butler, Adv. Heterocyclic Chem., 1977, 21, 323.

15. D. Dhambi, and D. Sharma, Indian J. Chem., 2009, 48B, 1006.

16. R.A. Batey, and D.A. Powell, Org. Lett, 2000, 2, 323.

17. M. Kidwai, P. Mishra, R.K. Saxena, Monatsh Chem., 1998, 129, 961.

18. J. Wu, L. Zhang, and T.N. Diao, Synlett., 2005, 1, 2653.

19. B.A. Baviskar, B. Baviskar, and M.R. Shiradkar, Eur. J. Chem., 2009, 6, 196.

20. B.D. Naik, and K.R. Desai, Asian J. Chem., 2004, 16, 1749.

21. S.B. Parskar, C.P. Amonkar, and S.G. Tilve, Indian J. Chem., 2009, 48B, 1336.

22. M. Kidwai, R. Venkataramanan, and B. Deve, Metal Based Drugs, 2002, 5, 283.

23. V.K. Ahluwalia, H.R. Sharma, and R. Tyagi, Tetrahedron, 1986, 42, 4045.

24. A.D. Mishra, J. Institute of Science and Technology, 2009, 16, 135.

25. V. Srivastava, S. Sen, and R. Shekhar, Indian J. Chem., 1994, 33B, 344.

26. M. Kidwai, P. Kumar, and Y. Goel, Indian J. Chem., 1997, 36B, 175.

27. H.W. Seeley, and P.J. Van Denmark, Microbes in Actions, WH Freeman and Co. USA, 1972.

28. S.K. Srivastva, R. Yadav, and S.D. Srivastava, Indian J. Chem., 2004, 43B, 399. 